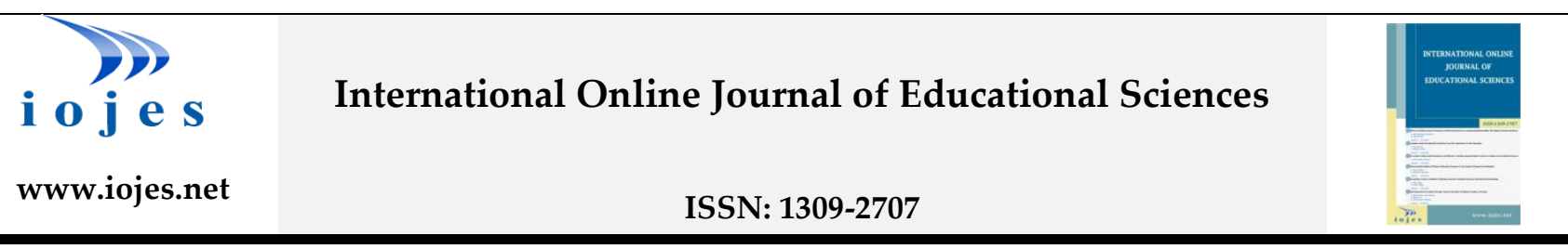

\title{
Teachers' Views on the Extracurricular Activities in Schools within the Scope of Classroom Management in Turkey
}

\section{Research Article}

\section{Mustafa ERSOY ${ }^{1}$, Ihsan TOPCU ${ }^{2}$}

${ }^{1}$ Sivas Cumhuriyet University, Faculty of Education, Department of Education Technology, Sivas, Turkey, ORCID: 0000-0002-7320-8844

2 Sivas Cumhuriyet University, Faculty of Education, Department of Education Technology, Sivas, Turkey, ORCID: 0000-0002-6712-3238

To cite this article: Ersoy, M., \& Topcu, I. (2021). Teachers' views on the extracurricular activities in schools within the scope of classroom management in Turkey, International Online Journal of Educational Sciences, 13(1), 209-301.

\begin{tabular}{|c|c|}
\hline ARTICLE INFO & ABSTRACT \\
\hline Article History: & $\begin{array}{l}\text { One of the main functions of the schools is to provide extracurricular activities for the students and } \\
\text { thus contribute to their multi-faceted development by enabling them to have a better time out of }\end{array}$ \\
\hline Received: 06.12.2020 & $\begin{array}{l}\text { lessons. Students need to enjoy their time by joining such activities more and more at our present } \\
\text { time. This study aims at finding the benefits of these activities for classroom management and what }\end{array}$ \\
\hline Available online: & teachers think about the adequacy of these activities. It is totally based on the teachers' views who \\
\hline 01.02.2021 & were chosen for this research. It is a qualitative study and 10 teachers from different branches were \\
\hline & selected through purposive sampling. They were interviewed using semi-structured forms. The \\
\hline & forms were prepared by the researchers. The questions in the interview form were prepared to be \\
\hline & consistent with the aim of the study. Descriptive and content analysis methods were used in data \\
\hline & analysis. Codes and themes were identified and arranged as frequency tables. Teachers' opinions \\
\hline & were categorized and then the findings were interpreted. According to the results obtained from the \\
\hline & study, teachers believe that club activities are effective in many areas of students' development but \\
\hline & are not be carried out at desired level in schools because of several reasons. \\
\hline
\end{tabular}

Keywords:

C 2021 IOJES. All rights reserved

School activities, extracurricular activities, classroom management

\section{Introduction}

Morin (1999) defines education as a comprehensive and multi-factor process. A contemporary education program has a continuous development and change, it is not limited to in-class activities, it is expected to be continued outside of the classroom in line with the main objectives of education and it is expressed as a process that includes evaluation with many activities at the end. Since student-centered education and teaching approaches are valid at our present time, it is possible to see a desired level of

${ }^{1}$ Corresponding author's address: Sivas Cumhuriyet Üniversitesi

Telephone: +905306309258

e-mail: mstfrsy@gmail.com

DOI: https://doi.org/10.15345/iojes.2021.01.019 
development in the classroom environment where individual differences are considered (Ekici, Bayraktar and Uğur, 2009).

Even if the teachers' in-class plans and preparations are at the desired level during the teaching process, it may not be at the desired level for the objectives and behaviors to be gained by the students during the classroom activities. Extracurricular activities are very important for students to produce their own knowledge by reprocessing the data and information they receive during the course in their minds and giving them subjectivity and increasing their ability to use this knowledge thus their understanding by experience and study, when necessary (Albayrak, Yıldız, Berber and Büyükkasap, 2004). Extracurricular activities were as important in the past as they are today. Freeman $(2017,14)$ reports the presence of extracurricular activity programs in Athens, Sparta and during the Hellenistic periods, as well as the Renaissance. The situation is still valid today. Extracurricular activities are a good resource for students, an opportunity for them to learn both academic and non-academic skills and to develop their relationships with other students and teachers at the school, and contribute to the intellectual and social development of students (Stearns \& Glennie, 2010, p. 307).

Extracurricular activities may include clubs, athletic opportunities, dance line or cheer teams, Scouts, drama or theater, youth groups, student council, and club sports. There is substantial interest in how teenagers are spending their leisure time outside the school day, and what types of activities are important to their development. There are studies that support either being involved, being over-involved, or not being involved at all in extracurricular activities and how participation can impact what becomes of teens in the future based on participation in activities outside the school day (Wilson, 2009, p. 1).

Demirel (2006) defines the training program as a set of learning experiences provided to students through planned activities at school and out of school. In addition to the curriculum, there are special days celebrated in the school, excursions, courses, guidance and health services and extracurricular activities (now known as student clubs), all of which enable the achievement of the goals of national education for the students. Extracurricular activities are very important for the realization of the desired level of learning in our country where the intensive information transfer approach is generally adopted during the course of the course.

Many studies in the literature revealed that students' participation in extracurricular activities contribute to their academic achievement (Guest and Schneider, 2003; Eroğlu, 2008; Wilson, 2009; Massoni, 2011; Sarı, 2012; Orhan-Özen, 2017). “In a study by Harvard Family Research Project (HFRP, 2008), it is argued that beyond academics, a lot of afterschool programs focus on improving students' social and developmental outcomes, such as self-regulation, selfesteem, self-concept, and social skills, and collaboration" (as cited in Kayalar, 2016, p. 8). With social club activities, students can gain self-confidence and learn to take responsibility as a member of a group. They can develop themselves in terms of managing time and planning. They can cooperate with their friends, develop their skills and abilities (Arabacı and Akgül, 2012).

Brown and Evans (2002) found that participation in extracurricular activities showed a linear relationship with students' commitment to school (in Sar1, 2012, p. 74). This could be an important strategy for developing high level of commitment among students. Participation in extracurricular activities encourages students to perceive their relationship with their schools more positively and develop their commitment to school (Finn, 1989; Mahoney, 2000, in Sarı, 2012, p. 75). 
Extracurricular activities are very important for school life in terms of many ways. For this reason, the relevant regulations in the Turkish education system stipulate that extracurricular activities should be held for the following purposes (MoNE, 2017, Artickle, p. 7):

- To develop a sense of self-confidence and responsibility in students,

- To protect students from violence and harmful habits,

- To provide students with new interests and skills,

- Allowing students to demonstrate their talents,

- To keep national, moral and cultural values alive, to spread them and to transfer these values to new generations,

- To encourage the awareness of volunteering in students,

- To raise awareness of human rights and children's rights among students. Also, Social activities should be carried out in scientific, social, cultural, artistic and sportive fields.

However, it is important and necessary to put them into practice as well as legal regulations. It is also necessary to reveal the level of students' participation to these activities, which are also determined as a legal obligation, and what is required for more effective student participation.

Craft (2012, p. 2) specifies that there is a strong association between student involvement in extracurricular activities and improved attendance, behavior, and academic performance and also cites from Reeves (2008) that all students who participate in some type of extracurricular activity perform better than students who are not involved. Today, all stakeholders are making a significant effort to ensure the effectiveness of schools. It is a known fact that extracurricular activities also have an important place for student outcomes and school effectiveness. In this study, the participation of students to these extracurricular activities, teachers' attitudes towards these extracurricular activities and obstacles to these activities in schools are investigated through the participants' views. "Extracurricular activities are important in achieving the educational goals, form student character and need further research, which reveals its contribution in the student's behavior and modify it" (Aleid, 2016, p. 33). The results will be helpful for all parts, mainly for students. They will also contribute to the planning and implementing of extracurricular activities at schools.

\section{Method}

This chapter presents information about the research model, study group, data collection tool, data collection, and data analysis.

\section{Model}

In the research, phenomenology design, a qualitative research method is used. Creswell $(2009$, p. 13) defined phenomenological research as "a strategy of inquiry in \which the researcher identifies the essence of human experiences about a phenomenon as described by participants". The reason for that the qualitative approach has been preferred is in order to examine the related topic in depth. Qualitative research is, "rich in description of people, places, and conversations, and not easily handled by statistical procedures. Research questions are not framed by operationalizing variables; rather, they are formulated to investigate topics in all their complexity, in context" (Bogdan and Biklen, 2006, p. 2). Qualitative research focuses on the thick description of context and often emerges from situated problems in the field (Yildırım and Şimşek, 2005; Patton, 2015). "The best-known representatives of qualitative research studies and those that most embody the characteristics we just touched on are those that employ the techniques of participant observation and indepth interviewing" (Bogdan and Biklen, 2006, p. 2). 


\section{Study Group}

The study group consists of 10 branch teachers who are assigned at state secondary schools in Sivas, Turkey. "Sampling is a necessary step in terms of choosing people to interview, as Tracy (2013, p. 134 states and she adds that "Good qualitative researchers, at the very least, engage in purposeful sampling, which means that they purposefully choose data that fit the parameters of the project's research questions, goals, and purposes" (Tracy, S. 2013, p. 134). In this research, school teachers were/are selected through convenience sampling, one of the purposeful sampling methods. "In qualitative research, the instances (or samples) are likely to be chosen in a deliberate manner known as purposive sampling. The goal or purpose for selecting the specific instances is to have those that will yield the most relevant and plentiful data -in essence, information rich-given your topic of study" (Yin, 2016, p. 93). Demographic information of teachers is given in Table 1. The participants were coded as T1.... T10.

Table 1. Demographic information of participant teachers

\begin{tabular}{llllc}
\hline Code & Sex & Branch & Education & Experience \\
\hline T1 & Male & Counseling & Undergraduate & 13 \\
\hline T2 & Female & Religion and Morals & Graduate & 22 \\
\hline T3 & Male & Technology & Undergraduate & 16 \\
\hline T4 & Female & Turkish & Graduate & 14 \\
\hline T5 & Female & Turkish & Undergraduate & 15 \\
\hline T6 & Male & Science & Graduate & 23 \\
\hline T7 & Male & Biology & Graduate & 13 \\
\hline T8 & Female & Social Sciences & Undergraduate & 7 \\
\hline T9 & Female & English & Undergraduate & 6 \\
\hline T10 & Male & Math & Undergraduate & 14 \\
\hline
\end{tabular}

As seen in the table, a total of ten teachers, five males and five females, participated in the study. Four of them have graduate degrees and others have undergraduate degrees. Their teaching experience varies from six to 23 years.

\section{Data Collection Tool}

In this study, in-depth interview method which is one of the data collection ways in qualitative research was used as data collection tool. "Interviews can take many forms, but for simplicity's sake all forms could fall into either of two types: structured interviews and qualitative interviews. Doing qualitative interviews is likely to be the overwhelmingly dominant mode of interviewing in qualitative research" (Yin, 2016, pp.140141).

Data were collected via interview form developed by the researchers after receiving two expert reports about it. Interview form consisted of four open ended questions to clarify the research topic. The school administration was informed of the meetings and appointments were made before the interview meetings. It was done at the pre-determined date and time in the teachers' free hours. Interviews lasted an average of 20 minutes. During the interviews, scientific and ethical principles were taken into consideration and attention was paid not to be a guiding the interviewees.

The participants answered the following questions:

1) How do you implement extracurricular activities and what are the reasons not to implement them effectively in your school?

2) In which areas of personal development do extracurricular activities contribute to students? 
3) What are the positive effects of extracurricular activities on the effectiveness of classroom management?

4) What are your suggestions for extracurricular activities to contribute to the personal development of students?

In a qualitative study, the concepts of credibility, consistency, transferability, and confirmability are used instead of validity and reliability (Roberts and Priest, 2006; Merriam, 2009; Creswell, 2016; Yin, 2016 ). In order to ensure the maximum level of credibility, attention was paid to being objective in the interviews and the responses were revised and arranged objectively. In terms of transferability, the data analysis processes were explained in detail and clearly. The data and coding were repeated by two other experts. Consistency was obtained by confirming the research questions with different data sources.

\section{Data Analysis}

The notes taken during the interviews were rewritten after the interview. Descriptive analysis and content analysis were used in the interpretation of interview data. The first step in analysis is to have the text database available. This means transcribing the interview and developing a database. It involves preparing the data for data analysis. The next step would be engaging in the general procedure of data analysis. Then the process of coding the data begins. This involves determining what is being said and assigning a code label to a text passage. Grouping similar codes together to build evidence of support for broader categories of information is also another step. A final aspect of data analysis consists of reflexivity, in which the researcher is conscious of how his/her background and personal experiences shape their interpretation of the database (Elo and Kyngas, 2008; Creswell, 2016, p. 334).

In this study, similar processes were followed for the data analysis. The titles listed the content analysis stages, first sub-categories, then general categories and finally the main category. For each category and subcategory frequency tables were prepared. The opinions of the participants, which will show the reason for the category and sub-category, were directly quoted (Elo and Kyngas, 2008). So, the data were analyzed in four stages as suggested in the literature: (1) coding the data, (2) finding themes, (3) editing codes and themes, (4) identifying and interpreting the findings with descriptive analysis.

\section{Findings}

\section{Implementation of Extracurricular Activities in Schools}

Participants' views on whether club extracurricular activities are implemented are given in two themes as "yes, implemented effectively" and "no, not implemented" and their explanations are given in five categories in the Table 2.

Table 2. Views on the implementation of extracurricular activities

\begin{tabular}{|c|c|c|c|}
\hline Themes & f & Category & f \\
\hline \multirow{2}{*}{ Yes, implemented } & \multirow{2}{*}{4} & Enough extracurricular activities & 1 \\
\hline & & we use time efficiently & 3 \\
\hline \multirow{4}{*}{ No, not implemented } & \multirow{4}{*}{6} & Not enough time & 2 \\
\hline & & Legal regulations & 1 \\
\hline & & Crowded classes & 1 \\
\hline & & Intensive courses & 2 \\
\hline Total & 10 & & 10 \\
\hline
\end{tabular}


Most of the participants $\mathrm{f}(6)$ stated that extracurricular activities were not implemented effectively. The participants stated the time problem and course intensity as the reasons. A 13-year experienced counseling teacher expressed his opinions as follows:

"We need extra time for these activities. Teachers and students do not have enough time to plan, apply and carry out these activities." T1

A 15-year experienced Turkish language teacher says: "Weekly activities do not include such activities, so teachers do not take time and do these activities at an additional hour." T5

Similarly, another participant (T7) emphasizes the adequacy of legal regulation. In fact, Turkish educational legislation has enough enforcements and sanctions on extracurricular activities. However, when and how these activities will be carried out in daily programs are not given exactly. Therefore, there are gaps about when exactly such events would take place, out of the lessons.

Two participants (T2 and T8), gave the reason of intensive courses. It is an accepted fact that the school curriculum is intense in Turkey. Moreover, rather than participating in social activities, students are expected to have more academic success. This limits students' participation in extracurricular activities.

The lessons are so intense that students don't have the opportunity to have other options. Grades 7 and 8 are already concerned with central exams. There is nothing other than solving multiple tests for preparation to those exams. The parents of the students are more exam-oriented than students. They want lessons like music and painting to be used for exam preparation, as well. Perhaps they (parents) are right. They must consider the future of their children. T2

In Turkey, parents insist on sending their children to university. Therefore, lessons that are important for social activities such as Painting, Music and Physical Education are not considered important by parents. This often restricts students' participation in extracurricular activities considerably.

One of the factors that restrict the participation of students to social events is crowded classes in Turkey. Although the number of students per teacher and the number of students in classes have decreased in recent years, one of the participants, $\mathrm{T} 2$, sees this as a reason preventing participation in extracurricular activities.

Four of the participants stated that extracurricular activities were implemented effectively. Three participants (T3, T6, T10) stated that extracurricular activities can be done if teachers can use time effectively. Participant T6, a 23-year experienced Science teacher expressed his views as "When teachers use their time efficiently, club activities are effectively implemented."

It is true that we are so busy with the courses. Our conditions and physical facilities are not very good either. But it is possible to do something when you want. Sometimes parents say that such activities are not needed. But their children are happy when they participate in these activities. They (parents) also feel happy when they see their children are happy. T3

\section{Contribution of Extracurricular Activities to Students' Development}

Participants 'views on the contribution of extracurricular activities on students' personal development areas are presented in 4 themes and 7 categories. Table 3 shows these themes and categories. 
Table 3. Contribution of extracurricular activities to students' development

\begin{tabular}{|c|c|c|c|}
\hline Themes & $\mathrm{f}$ & Category & $\mathrm{f}$ \\
\hline \multirow{2}{*}{ Interaction and communication } & \multirow{2}{*}{4} & Gaining sociality & 1 \\
\hline & & Effective communication & 3 \\
\hline Belonging to a group & 1 & Group belonging & 1 \\
\hline \multirow{2}{*}{ Developing areas } & \multirow{2}{*}{2} & Physical development & 1 \\
\hline & & Mental development & 1 \\
\hline \multirow[t]{2}{*}{ Self-reliance } & \multirow[t]{2}{*}{3} & Responsibility awareness & 1 \\
\hline & & Self-reliance /Self-confidence & 2 \\
\hline Total & 10 & & 10 \\
\hline
\end{tabular}

According to the participants, the most striking theme in the impact of extracurricular activities on students' personal development is interpersonal relations and effective communication.

The classroom is an area where educational activities take place. Positive relationships between students reflect positively on classroom management. The quality of communication and interaction among the students is also the main factor that creates positive relations in the classroom. In this respect, it can be said that extracurricular activities have significant effects on classroom management. In this study three participants (T2, T3, T8) stressed the importance of communication among students. A 22-year experienced Religion and Morals teacher quoted this: "Social and extracurricular activities allow students to know each other better and cooperate closely. The interaction between them increases. Harmony increases. Contrary to popular belief, students learn a lot from each other. Interaction and collaboration lead students to learn more and more". T2

Another participant stated that "Using communication correctly in interpersonal relationships influence communication with other students. This communication could be developed in social activities." T3

One of the skills that students need to gain is to make them socialize. Socialization of students improves their thinking skills along with many benefits. One participant (T7) who emphasized this stated:

Different areas of the brain are stimulated when our children break the routine home-school-classrooms chain, that is, when they engage in any social activity or sporting activity. Accordingly, the right and left brain work more coordinated. Thus, our socialized children also could think differently and evaluate events differently. T7

Two participants (T4, T9) talked about the importance of self-reliance and self-confidence. Participant T4, a six-year experienced English language teacher said: "Self-confidence is an important feature in the development of individuals. Schools should create a school culture that will contribute to the development of students' self-confidence. Schools should give their students some opportunities to take part in social activities because they have a very important impact on the development of students' self-confidence." T4

Participating in such activities contributes to the mental and spiritual developments of each student. T1

It makes them responsible and they can learn to take responsibility if they join in extracurricular activities. T8

Social activities give students a sense of accomplishment by showing that they will be successful in different areas. As students experience their sense of achievement, their self-confidence increases. T10

\section{Effects of Extracurricular Activities on Classroom Management}

Teachers' views on the effect of participating in extracurricular activities on classroom management is shown in Table 4 . They are presented in 2 themes and 5 categories, as seen in the table. 
Table 4. Teachers' views on the effect of extracurricular activities on classroom management

\begin{tabular}{|c|c|c|c|}
\hline Themes & $\mathrm{f}$ & Category & $\mathbf{f}$ \\
\hline \multirow[b]{2}{*}{ Discipline } & \multirow[b]{2}{*}{4} & Commitment to classroom rules & 2 \\
\hline & & Self-discipline & 2 \\
\hline \multirow{3}{*}{ Motivation } & \multirow{3}{*}{6} & Willingness to the classroom activities & 1 \\
\hline & & Attending classes regularly & 3 \\
\hline & & Cooperation with classmates & 2 \\
\hline Total & 10 & & 10 \\
\hline
\end{tabular}

One of the most important dimensions of classroom management is motivation. Motivation can be defined as directing individuals to desired behaviors. The most important effects of extracurricular activities in the context of classroom management are the positive effects on students' motivation. Motivation has an important place in education (Orhan-Özen, 2017). Highly motivated students develop a positive attitude towards cooperation and learning together. They have positive expectations for the future and can set goals in the learning process. Motivated students take more responsibility in learning activities.

In this study six participants expressed that extracurricular activities have positive effects on student motivation in different ways. Three participants (T3, T8, T10) said that extracurricular activities affect student attendance. One participant (T2) emphasized that students 'desire to participate in classroom activities increased. Two participants (T5, T9) stated that the cooperation of the students with their friends increased.

Extracurricular activities lead to positive attitudes of students towards school T8.

The students love school much more and willingly continue to lessons. T3, T10

They develop better relationships with friends. Students are more enthusiastic in class activities. T2

The other important dimension of the classroom management is class discipline. Discipline means ways of controlling students' negative behaviors in the classroom. According to the findings of this study, participation in extracurricular activities leads the students to the desired behaviors. Students pay more attention to class rules. Such activities help students to develop self-discipline.

Extracurricular activities help students take responsibility. T1

Students can develop better relationships through extracurricular activities. T7

Increases responsibility and self-confidence. T4

Feelings of school commitment are increased, and they adhere more to the rules. T6

\section{Suggestions for Effective Extracurricular Activities in Schools}

The participants' suggestions for extracurricular activities are presented in 5 themes with 8 categories. The teachers presented the suggestions for extracurricular activities to be carried out at the expected level. their suggestions are given in Table 5.

Table 5. Teachers' suggestions to improve extracurricular activities

\begin{tabular}{llll}
\hline Themes & $\mathbf{f}$ & Category & $\mathbf{f}$ \\
\hline \multirow{2}{*}{ Physical opportunities } & 4 & Materials & 2 \\
\cline { 3 - 4 } & & Physical conditions & 1 \\
\cline { 3 - 4 } & & Suitable places & 1 \\
\hline School management & 1 & Support to the students & 1 \\
\hline \multirow{2}{*}{ Students } & 3 & Students should be more active & 2 \\
\cline { 3 - 4 } & 1 & Assigning responsibility to students & 1 \\
\hline Legislation & 1 & Decreasing procedures & 1 \\
\hline Teachers & 10 & & 10 \\
\hline Total & & & \\
\hline
\end{tabular}


When we look at the answers to the question of what should be done to make extracurricular activities more effective, it is seen that the opportunities are emphasized. The participants suggested improving the facilities of the school in order to increase extracurricular activities. As will be accepted, extracurricular activities are possible with the physical conditions and equipment of the school. It is known that physical conditions of schools in Turkey are generally not enough. From this point of view, it is understandable that the improvement of physical conditions is recommended as a priority. The direct quotations from the participants are given below:

Participation in extracurricular activities is largely related to the school's possibilities. In order to increase these activities, it is necessary to provide material support to schools. T3

Improving physical conditions is the best solution. Students needs to join sportive activities. Social activities. Better conditions supply better opportunities for students T6

Creating enough open and closed places can increase participation to extracurricular activities. T2

Students should be encouraged for extracurricular activities. T7

Parents' support should be provided. T9

Social activities should be organized to attract the interest of the students. T5

Reduce activities procedures $\mathrm{T} 1$

These quotations show that increasing social activities depends to a large extent on the school's facilities and physical capacity. It is also important to encourage students and provide parents' support. School principals, teachers and all parties of schools should take these into account.

\section{Discussion and Conclusion}

Based on the findings obtained in the study, the opinions of teachers about the students' participating to social activities on multi-faceted development of students and classroom management were arranged for the purpose of the research. The level of participation in extracurricular activities and the applications of these activities were investigated. it is also aimed to find out what can be done to increase extracurricular activities.

Related literature shows that students have more positive academic and social educational experience when they are more engaged to extracurricular activities. Yet this study showed that participating in extracurricular activities is not at desired level. Considering the importance of extracurricular activities for the development of students, schools should encourage their student to participate in those activities. Stearns \& Glennie, (2010, p. 308) have found that some types of activities, particularly academic and sports activities, are associated with the student outcomes of academic performance and staying in school. Participation in activities also increase students' commitment to school, thus lowering their risk of dropping out.

The participants do not find extracurricular activities enough in their schools. The level of participation in extracurricular activities in schools is low. This result is similar to the findings in the literature (Özkaptan, 2007; Gökyer and Zincirli, 2011). The possible reason for this is focusing on academic success in schools. It can be interpreted that academic success-oriented students focus more on studying for their central exams and this prevents them to engage in other social and extracurricular activities. It becomes more evident when students are in the $11^{\text {th }}$ and $12^{\text {th }}$ grades as the university entrance exams approach.

The second reason is the lack of facilities in schools. As we know well, such activities require good physical conditions. The facilities that the schools have are important. Third reason might be that teachers and school administrations do not give the necessary importance to such activities and the other reason might be socioeconomic level of families.

Participants state that social activities enable improvements to students in different areas of personal development. The participants think that extracurricular activities are beneficial for the development of personality, responsibility and self-reliance. It is stated that extracurricular activities as well as instructional 
activities are necessary for the multidimensional development of students. Massoni (2011), too, summarizes it as "Extracurricular activities are a part of students' everyday life. They play important roles in student's lives. They have positive effects on student's lives by improving behavior, school performance, school completion, positive aspects to make successful adults, and social aspects. As teachers, we need to be aware of the effects that extracurricular activities have on education."

It was revealed that extracurricular activities contributed to effective communication and interaction (Sağlam and Yayla, 2014). It is thought that it promotes physical and mental development as well as improving interpersonal relationships. Self-confidence, which is one of the important gains for students, and the ability to take responsibility and succeed accordingly, can be improved by extracurricular activities. Students can learn to belong to a group. Students develop team spirit. Akar and Nayir (2015, p. 168) reached the similar results.

As for the participants' suggestions for increasing social activities and making students more efficient, they are improving physical conditions, encouraging students, providing family support. Teachers complain about not being able to provide enough materials and sources for extracurricular activities. So, schools should be supplied such sources. Although the technological and financial difference in provinces, districts and rural areas in Turkey is gradually decreasing, social activities are conducted to some extent with the help of many projects today.

\section{Recommendations}

- More time for extracurricular activities is required. So, enough time should be provided.

- Students' participation in these activities should be rewarded.

- Cooperation with parents is important. school management and teachers should cooperate with parents. 


\section{REFERENCES}

Akar, F., \& Nayir, N. F. (2015). Examining effectiveness of social clubs in educational organizations: need for change in implementation, Pegem Journals of Education and Instruction, 5(2), 167-186.

Albayrak, M., Yıldız, A., Berber, K., \& Büyükkasap, E. (2004). Parents' ideas about activities out of lesson and student behavior interested with activities. Kastamonu Education Journal, 12(1), 13-18.

Aleid, A. S. (2016). The effectiveness of student extracurricular activities in evaluating violent behavior among students in the preparatory year at Hail University. Journal of Education and Practice. 7(18), 32-43.

Annu, S., \& Sunita, M. (2014). Extracurricular activities and student's performance in secondary school. International Journal of Technical Research and Applications, 2(6), 08-11.

Arabacı, İ. B., \& Akgül, D. (2012). Elementary school students' views toward the social club activities (Sample of Bitlis) New-Education Sciences, 7(1), 485-495.

Bogdan, R., \& Biklen, S.K. (2006). Qualitative research for education: An introduction to theory and methods. (5 $5^{\text {th }}$ Ed.). Pearson.

Craft, S. W. (2012). The impact of extracurricular activities on student achievement at the high school level, PhD Thesis. The University of Southern Mississippi. https://aquila.usm.edu/dissertations/543

Creswell, J. W. (2009). Research design: Qualitative, quantitative, and mixed methods approaches. (3 $3^{\text {rd }}$ Ed.). SAGE Publications, Inc.

Creswell, J. W. (2016). 30 Essential skills for the qualitative researcher. SAGE Publications, Inc.

Demirel, Ö. (2006). Program development for education. Ankara: PegemA Publishing.

Ekici, S., Bayrakdar, A., \& Uğur, O. (2009). The attitudes of managers and students of secondary schools, towards interscholastic activities. Journal of International Human Sciences, 6(1), 430-444.

Elo, S., \& Kyngäs, H. (2008). The qualitative content analysis process. Journal of Advanced Nursing, 62(1), 107115.

Eroğlu, E. (2008). Problems encountered during educational clubs and solution suggestions of these problems in primary schools (Elmadağ sample). Master's Thesis, Hacettepe University, Social Sciences Institute, Ankara.

Freeman, R. (2017). The relationship between extracurricular activities and academic achievement. (a PhD Thesis in Educational Leadership). National Louis University, National College of Education.

Gökyer, N., \& Zincirli, M. (2011). The perceptions of advisors and social club representative students on the level of realization of social club activities performed. E-journal of New World Sciences Academy, 6(2), 1836-1851.

Guest, A., \& Schneider, B. (2003). Adolescents' extracurricular participation in context: the mediating effects of schools, communities, and identity. Sociology of Education, 76(2), 89-109.

Kayalar, F. (2006). Views of teachers on the benefits of after-school programs and summer programs in terms of social emotional learning. Merit Research Journal of Education and Review, 4(2), 6-013.

Massoni, E. (2011). Positive effects of extracurricular activities on students, ESSAI, 9. Retrieved November 14, 2018 from http://dc.cod.edu/essai/vol9/iss1/27.

Merriam, S. B. (2009). Qualitative research: A guide to design and implementation. John Wiley \& Sons, Inc.

MoNE (2017). Turkish Ministry of National Education educational institutions regulation for extracurricular activities. Ankara. 
Morin, E. (1999). Seven complex lessons in education for the future. UNESCO Publishing.

Orhan-Özen, S. (2017). The effect of motivation on student achievement in (E. Karadağ ed.), The Factors Effecting Student Achievement. Springer International Publishing AG.

Özkaptan, E. (2007). Evaluation of recreational aspects of social club activities in private and public schools (Adapazarn intermediate school institution pattern), Master's Thesis, Sakarya University, Social Sciences Institute Sakarya.

Patton, M. Q. (2015). Qualitative research and evaluation methods: Integrating theory and practice (Fourth edition). SAGE Publications, Inc.

Roberts, P., \& Priest, H. (2006). Reliability and validity in research. Nursing Standard, 41-45.

Sağlam, A., \& Yayla, A. (2014). Teachers' opinions about the functions of social clubs applied in primary and secondary schools. Ahi Evran University Journal of Kirşehir Faculty of Education, 15(2), 279-296.

Sarı, M. (2012). An investigation of high school students' participation in extracurricular activities. Journal of Theoretical Educational Science, 5(1), 72-89.

Stearns, E., \& Glennie E. J. (2010). Opportunities to participate: Extracurricular activities' distribution across and academic correlates in high schools. Social Science Research, 39(2), 296-309.

Tracy, S. (2013). Qualitative research methods. West Sussex: John Wiley E Sons, Ltd Publication.

Wilson, N. (2009). Impact of extracurricular activities on students. (Master's Thesis). The Graduate School University of Wisconsin-Stout.

Yıldırım, A., \& Şimşek, H. (2005). Qualitative research methods in the social sciences. Ankara: Seçkin Publishing.

Yin, R. (2016). Qualitative research from start to finish (2nd Ed.). New York: The Guilford Press. 